\title{
Stability of the excavation face on a shield tunnel crossing beneath an existing tunnel
}

Fei Xue

Lecturer, Department of Civil Engineering, Shanghai University, Shanghai, China (corresponding author: fei_lin@126.com) (Orcid:0000-0002-7861-5684)
Mengxi Zhang

Professor and Doctoral Supervisor, Department of Civil Engineering, Shanghai University, Shanghai, China

When a shield tunnel crosses the route of an existing tunnel, the new tunnel will have great influence on the inner structure and the upper surface of the existing tunnel. The support force of the excavation face is an important factor in controlling the ground surface deformation. In the construction of shield tunnelling, the damage caused by insufficient supporting force at the excavation face is much greater than the damage caused by excessive supporting force. In this paper, Abaqus software is used to simulate the instability of the excavation face caused by the small support pressure of the excavation face when the tunnelling machine crosses the route of the existing tunnel at close range. The variation of the ultimate supporting force of the excavation face and the influence of the support force of the excavation face on the existing tunnel and the ground surface settlement are analysed for different horizontal distances between the excavation face and the existing tunnel. The results show that the existence of the existing tunnel has a significant impact on the ground settlement caused by the excavation of the new tunnel. Moreover, when the shield is pushed to the same position, different supporting pressures will produce different vertical deformation increments for the new tunnel segments.

\section{Notation}

$D \quad$ diameter of the new shield tunnel and existing tunnel

$K_{0} \quad$ lateral pressure coefficient

$Z \quad$ distance between the excavation face of the new shield tunnel and the centre of the existing tunnel

$\lambda \quad$ support stress ratio

$\sigma_{0} \quad$ initial horizontal earth stress

$\sigma_{\mathrm{s}} \quad$ stress value of the excavation surface support

\section{Introduction}

With the rapid development of cities, urban rail transit has entered the stage of high-speed construction, and engineering examples of new tunnels crossing existing tunnels are constantly emerging. The construction of new tunnels using short-distance shield tunnelling will lead to changes in the surrounding environment. When shield tunnelling crosses the route of existing tunnels, the new tunnels will have greater impact on the internal structure and the upper surface of the existing tunnels. Shield excavation makes the deformation mechanism of the surface and the existing tunnels very complex. Therefore, the control of surface deformation caused by construction is extremely demanding, and the supporting force of the excavation surface is extremely high. The magnitude of deformation is an important factor for controlling the surface deformation. In shield tunnel construction, the engineering hazards caused by insufficient support force on the excavation face are far greater than those caused by the surface uplift caused by excessive support force (Addenbrooke and Potts, 2001; Chapman et al., 2007; Hefny et al., 2004; Li et al., 2014; Ma et al., 2016; Xiao et al., 2011; Yu and Zhu, 2002).

For the study of stability of the excavation face, indoor and outdoor experiments, numerical simulations, theoretical analyses and field tests are often used. Miao et al. (2015) analysed the soil damage form and distribution range of shield tunnel excavation in sand and proposed the calculation of optimising the minimum supporting force of the excavation face by the wedge model. $\mathrm{Xu}$ et al. (2012) used a three-dimensional (3D) wedge model based on limit equilibrium theory to study the stability of the excavation surface of a super-large-diameter slurry shield. Jancsecz and Steiner (1994) used the principle of limit equilibrium to build a wedge model and analysed the ultimate support force of the excavation surface in the shield construction process and studied it. Moreover, the ultimate support force of the excavation face in the shield construction has been analysed and studied. The collapse of the excavation face has been used to simulate the failure mode of the excavation surface by using particle flow code software. The traditional wedge model has been optimised $\mathrm{CH}$ and Zhang, 2013).

In addition, some achievements have been made in the study of the soil arching effect. The soil arching effect refers to the transfer of pressure from moving soil to adjacent immovable soil, which is used to describe the phenomenon of stress transfer in soil. The concept of the soil arching effect has been put forward for more than 100 years and is widely used in geotechnical engineering. In 1883, the British scientist Isaac Roberts first discovered the 'granary effect' (Roberts, 1883). The pressure at the bottom of the particulate matter accumulated in the container does not change with the increase in the particulate matter at a certain height, which is commonly known as the 'arching effect'. In 1907, Russian scholar M. M. Protodyakonov theorised that if the excavation of the tunnel was not supported in time, the soil on the top of the tunnel would collapse continuously and form a parabola-shaped collapse arch (Protodyakonov, 1907). The 
establishment of this theory deepened the study of the natural balance arch in a loose medium. Terzaghi (1936) confirmed the existence of the arching effect in the field of soil mechanics through the falling baffle plate test; measured the changes in the vertical and horizontal earth pressures of the soil in the upper part of the baffle plate; and, along with the changes in the forces on the baffle plate moving down, proved that the seepage had no effect on the arching effect; he also thought that the vibration had only a small effect on the arching effect. Terzaghi (1943) proposed the formation mechanism of the soil arching effect based on the falling baffle test results, defined the soil arching effect and deduced the formula of loose earth pressure. Li et al. (2011) revealed the formation and development of a soil arch from the perspective of soil stress change by monitoring the change in soil stress state in front of the excavation face. Gao (2011) carried out a trapdoor test to simulate the excavation of a shield tunnel in a sandy soil layer; studied the transfer mechanism of vertical earth pressure in the upper part of the trapdoor; summarised the value of the lateral pressure coefficient $K_{0}$ in the soil arch area in and outside China; and compared this with the test results and gave the recommended value. Wu et al. (2015) improved the silo wedge model based on the consideration of the 3D soil arching effect in loose soil and the friction between the excavated soil and the cutterhead, and gave the distribution form of the soil pressure stress on the cutterhead in the loose area. Song et al. (2015) studied the influence of soil and water coupling on the soil arching effect above the shield excavation face, analysed the influence principle of groundwater on the soil arching height and analysed the influence of groundwater on the minimum support pressure of the excavation face combined with the wedge model.

It is not difficult to find that some existing achievements do not involve the stability study of the excavation face when crossing the route of existing tunnels (Anagnostou and Kovari, 1994; Chen et al., 2011; Lee and Ge, 2001; Zhang et al., 2011). In practice, the failure of the excavation face, collapse of the surface, cracking of the existing tunnel and water leakage, which are caused by the insufficient support pressure of the excavation face, are of great concern in projects. It is also not difficult to find that there are few studies on the stability of the excavation face when shield tunnelling passes a short distance from existing structures. This extreme construction situation is occurring more and more in urban underground construction. It is very important to study the stability of shield tunnelling passing a short distance from existing structures. The ultimate purpose of this paper is to analyse regularly the stability of the shield excavation face in cases of short-distance crossing by means of numerical calculation and theoretical analysis, to provide a theoretical reference for subsequent similar engineering construction. In this paper, the situation of a shield tunnel crossing beneath an existing tunnel is considered. The Abaqus software program is used to simulate the instability damage caused by too little support force of the excavation face. The change in the limit support force of the excavation face and the influence of support force value of the excavation face on the existing tunnel and ground subsidence are analysed for varying horizontal distances between the excavation face and the existing tunnel.

\section{Numerical simulation of the failure mode of the excavation face}

\section{Three-dimensional finite-element model}

A 3D model is established to simulate the instability of the excavation face caused by too little support pressure on the excavation face when the shield tunnel is positioned at different distances from the existing tunnel $(Z=1.5,3.0$ and $4.5 \mathrm{~m} ; Z$ denotes the distance between the excavation face and the existing tunnel). The size and meshing of the model are shown in Figure 1. The boundary condition of the model is set as follows: all sides limit its normal displacement, the bottom boundary is set to full constraint and the surface of the ground is set as a free plane, so that the change in the boundary condition will not have any effect on the vertical deformation of the model.
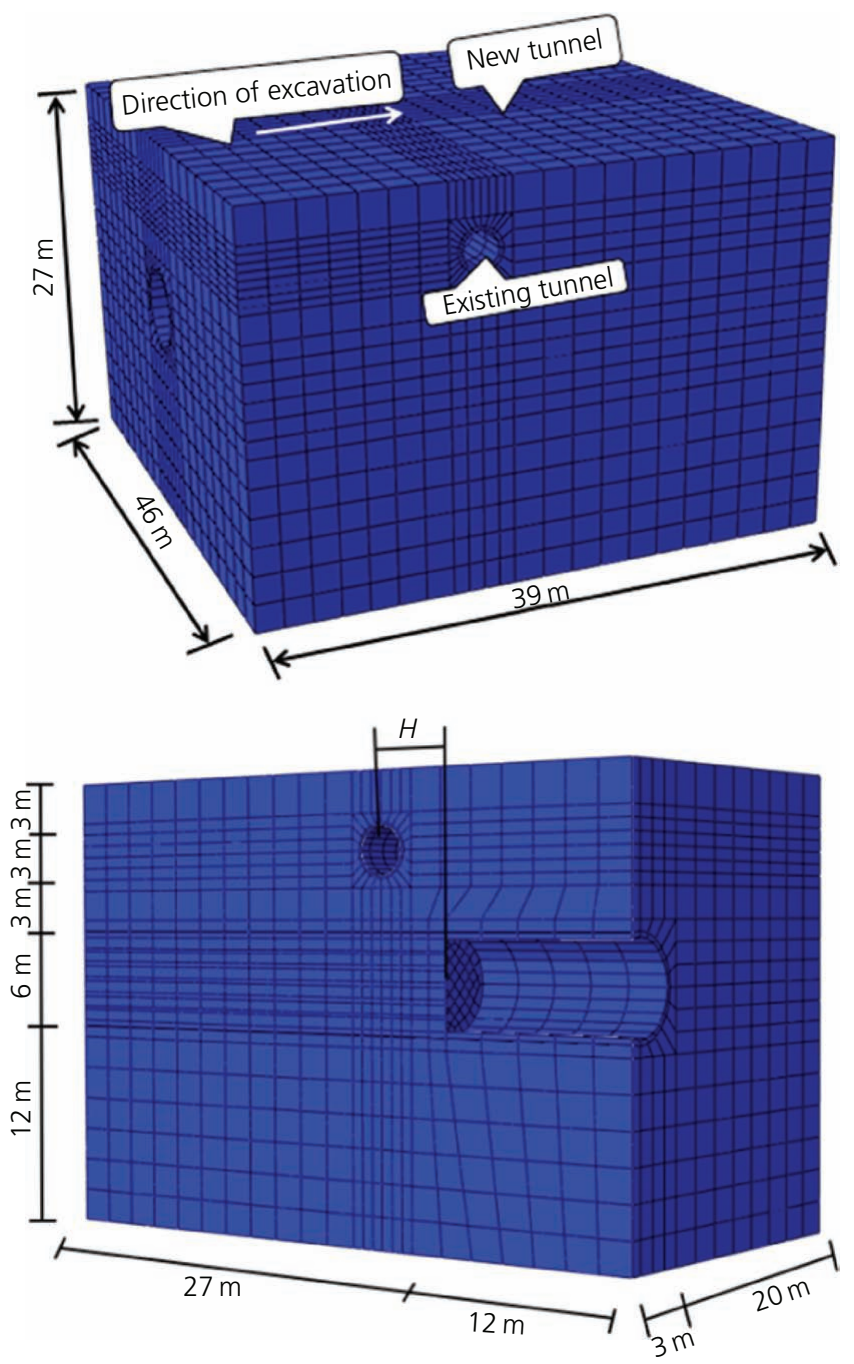

Figure 1. Three-dimensional finite-element method model of shield crossing 
It should be noted that in geotechnical engineering, the lateral pressure coefficient $K_{0}$ has a great influence on the damage of the excavation surface; however, in finite-element calculation, $K_{0}$ cannot be given a dynamic change process, so in the calculation, $K_{0}$ is always considered to remain unchanged.

\section{Model parameter selection}

The 3D hexahedron eight-node solid element C3D8R is used in the soil and concrete segment, and the total number of solid elements in the model is 12305 . Because the focus of this study is the stability of the excavation surface, in order to facilitate the calculation, the soil in the model is set as homogeneous soil. The constitutive model of the soil is the Mohr-Coulomb model, and the physical and mechanical parameters of the model are shown in Table 1. The inside and outside diameters of the existing tunnel are 2.6 and $3.0 \mathrm{~m}$, respectively, and the thickness of lining segments is $0.2 \mathrm{~m}$. The inside and outside diameters of the new tunnel are 5.2 and $6.0 \mathrm{~m}$, respectively, and the thickness of lining segments is $0.4 \mathrm{~m}$. The concrete used for the lining of the new and existing tunnel is C50, and according to the Chinese design code, the elastic modulus of the tunnel is $30 \mathrm{GPa}$ and its Poisson's ratio is $0 \cdot 2$. Because the stability of excavation faces is the main focus of the study, the coupling effect between groundwater and soil is not considered.

\section{Simulation of shield construction}

When the dynamic process of shield tunnelling is simulated, shield tunnelling can be assumed to be discontinuous. In the Abaqus finite-element software, the birth and death element function is used to simulate the excavation process, and the method of changing the material parameters of the equipollent layer is used to realise the process of gap closure and synchronous grouting at the tail of the shield. This paper focuses on the stability of the excavation face. Therefore, using one excavation to the designated location, the initial force is applied to support the excavation face, and then the support force is released gradually until the excavation face is destroyed.

\section{Determination of ultimate support stress}

In this paper, the catastrophe criterion is used to determine the boundary support stress of excavation. According to the basic principle of stability theory, the limit support force is defined as the support force when a slight change in the support force leads to a sudden change in the horizontal displacement at the centre of the excavation face. The support force of the excavation face refers to the support force exerted by the centre of the excavation face. In order to express the relationship between the supporting force of the excavation face and the horizontal static earth pressure of the original stratum in the centre of the tunnel, the concept of supporting stress ratio is introduced
1. $\lambda=\sigma_{\mathrm{s}} / \sigma_{0}$

where $\lambda$ is the support stress ratio; $\sigma_{\mathrm{s}}$ is the stress value of the excavation surface support; and $\sigma_{0}$ is the initial horizontal earth stress.

\section{Analysis of simulation results}

Change in limit supporting force on the excavation face The support force of the excavation face is set as the lateral static earth pressure at the centre of the excavation face, and then it is gradually decreased at a slow speed. The curve of the horizontal displacement of the excavation face is obtained with the support stress ratio. As the support stress ratio decreases, the horizontal displacement increases gradually. When the support stress ratio decreases to a certain extent, the horizontal displacement of the excavation face increases sharply. It is the moment when the excavation surface is unstable, and the support force is the minimum limit support force. Figure 2 shows the relationship between the support stress ratio and the horizontal displacement of the excavation centre.

From Figure 2, it can be seen that the horizontal displacement of the midpoint of the excavation face increases gradually with the decrease in the support stress ratio. When the support stress ratio decreases to a certain value, the displacement increases rapidly. When the support stress ratio hardly decreases, the soil deformation still increases rapidly, which indicates that the soil has been destroyed at this time, and the corresponding support

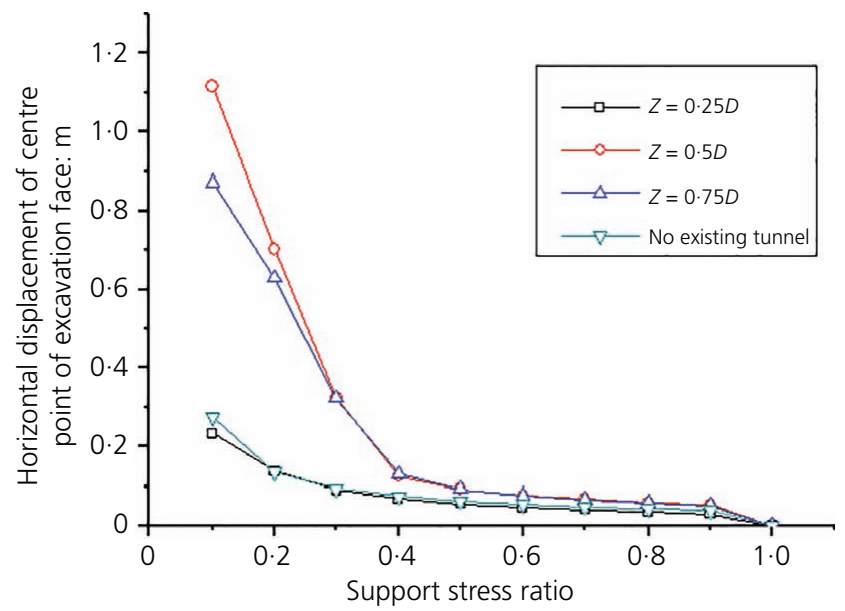

Figure 2. Relation between the support stress ratio and the midpoint horizontal displacement of the excavation face

Table 1. Physical and mechanical parameters of the soil

\begin{tabular}{|lccccc} 
Parameter & Density: $\mathbf{k N} / \mathbf{m}^{\mathbf{3}}$ & Cohesive force: $\mathbf{k P a}$ & Internal friction angle: & Modulus of elasticity: MPa & Poisson's ratio, $\boldsymbol{v}$ \\
\hline Value & 17 & 4.5 & 10 & 20 & 0.35
\end{tabular}


pressure value is the limit value. The steeper the curve is, the earlier the soil will enter the limit equilibrium state.

It can be seen from the figure that the horizontal displacement curve of the support stress-excavation midpoint almost coincides under the two conditions of $0 \cdot 25 D$ and no existing tunnel. At this time, the influence of the existing tunnel on the support force of the excavation face can be neglected, which is manifested in the fact that the setting of the support force is almost equal to that of no existing tunnel. Therefore, it is concluded that when the horizontal distance between the excavation face and the existing tunnel is $0 \cdot 25 D$, the existing

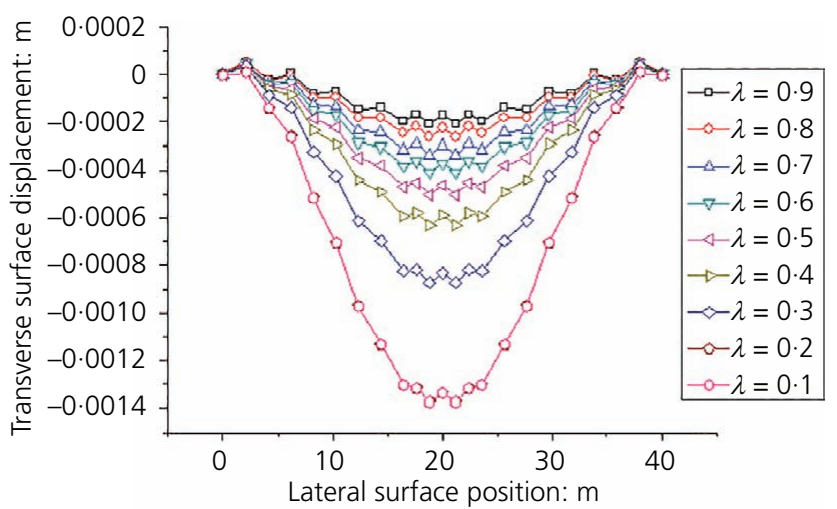

(a)

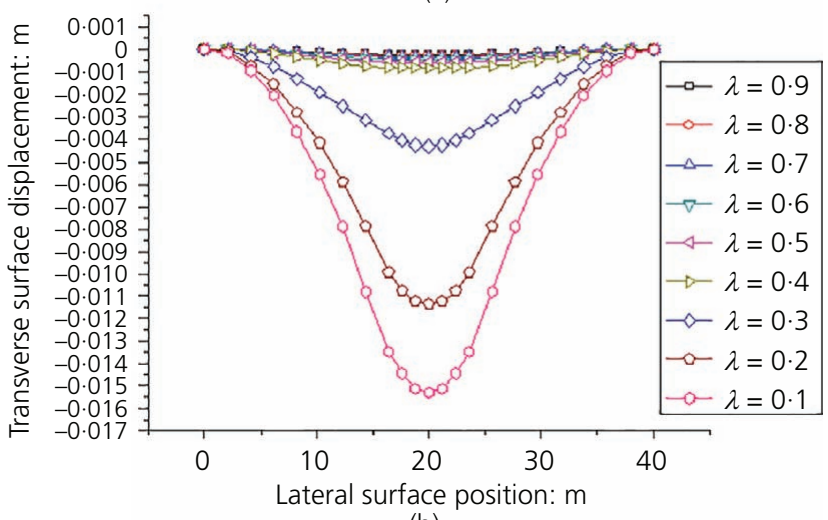

(b)

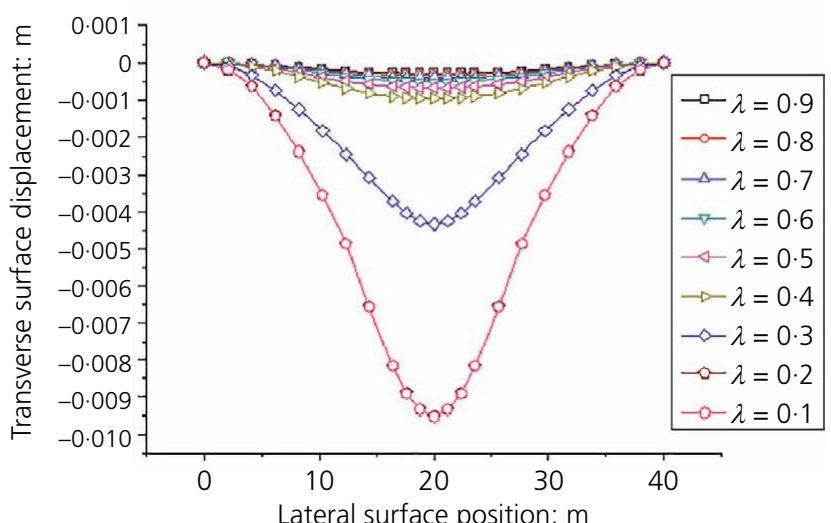

(c)

Figure 3. Transverse surface settlement curve with an existing tunnel: (a) $Z=0.25 D$; (b) $Z=0.50 D$; (c) $Z=0.75 D$ tunnel has almost no influence on the excavation face. By comparing the curves under different working conditions, it can be seen that when crossing approaches $(Z=0.75 D$ and $Z=0.50 D)$, the limit support pressure needed to maintain the balance of the excavation face of the existing tunnel is larger than that of the existing tunnel and the limit support force of the excavation face is slightly larger at $0.50 D$ than that at $0.75 D(Z$ stands for the distance between the excavation face of the new shield tunnel and the centre of the existing tunnel; $D$ stands for the diameter of the new shield tunnel and existing tunnel).

Transverse surface settlement above the existing tunnel

Surface settlement above the shield tunnel is caused by stratum loss during tunnelling. In addition to shield clearance and grouting factors, over-excavation caused by insufficient support force on the excavation face is also an important parameter. The Peck formula describes the ground settlement distribution above the tunnel as a settlement trough and has been verified in a large number of practical projects (Peck, 1969). The existence of existing tunnels will also affect the width and depth of the ground settlement trough. Because one-time excavation is set to the designated location in the model, the cumulative effect of deformation caused by prophase advance is not considered in the subsidence of ground surface in this section.

Figures 3 and 4 show the surface settlement curves along the transverse direction above the existing tunnel when the support stress ratio is between $0 \cdot 1$ and $0 \cdot 9$ for existing tunnel $(Z$ is $0 \cdot 25 D$, $0.50 D$ and $0.75 D$ ) and no existing tunnel, respectively. From the graph, it can be seen that all working conditions have similar laws - that is, with the increase in the support stress ratio, the surface settlement curves above existing tunnels tend to be gentle and the depth of the settlement trough decreases. The difference is that when the supporting stress is the same, the surface settlement of the existing tunnel is smaller than that of the case where there is no existing tunnel, but the influence range is enlarged. The reason is that the stiffness of the existing tunnel is much larger than that of the surrounding soil, which results in the shielding

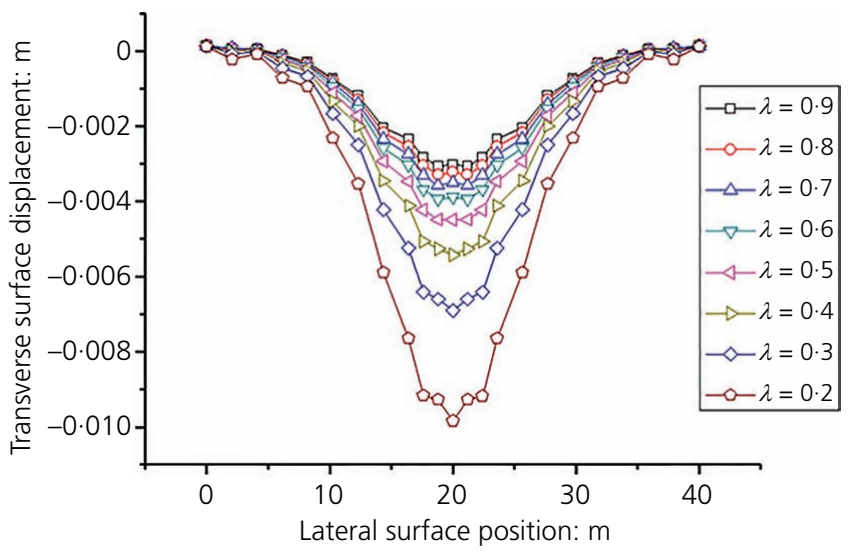

Figure 4. Transverse surface settlement curve without an existing tunnel 
effect and reduces the surface settlement and transfers the unloading effect of excavation to a farther area.

Figure 3(a) shows that when $Z$ is $0 \cdot 25 D$ and the support stress ratio decreases from $0 \cdot 9$ to $0 \cdot 3$, the maximum ground settlement above the existing tunnel changes by about $0.6 \mathrm{~mm}$, whereas when the support stress ratio decreases from $0 \cdot 3$ to $0 \cdot 2$, the maximum ground settlement above the existing tunnel increases by about $0.5 \mathrm{~mm}$. It can be seen that the stress ratio of the limit support is less than $0 \cdot 3$, which is a significant change area of the surface directly above the existing tunnel.

From Figures 3(b) and 3(c), it can be seen that when $Z$ is $0 \cdot 50 D$ and $Z$ is $0.75 D$ and the support stress ratio decreases from 0.9 to $0 \cdot 4$, the maximum ground subsidence above the existing tunnel changes by about $1 \mathrm{~mm}$, whereas when the support stress ratio decreases from $0 \cdot 4$ to $0 \cdot 3$, the maximum ground subsidence above the existing tunnel increases by about $3 \mathrm{~mm}$. It can be seen that the stress ratio of the limit support is less than $0 \cdot 4$, which is a significant change area of the surface above the existing tunnel.

From Figure 4, it can be seen that when there is no existing tunnel and the support stress ratio decreases from $0 \cdot 9$ to $0 \cdot 3$, the maximum ground settlement changes by about $4 \mathrm{~mm}$, whereas when the support stress ratio decreases from 0.4 to $0 \cdot 3$, the maximum ground settlement increases by about $3 \mathrm{~mm}$. It can be seen that the stress ratio of limit support of less than 0.3 is a significant change area of the surface.

Therefore, keeping the support pressure of the shield tunnelling face away from these significant changing areas is an important guarantee of controlling the deformation of the existing tunnel.

\section{Effect of the support stress ratio on the displacement and stress of the existing tunnel}

When the shield excavation face is pushed near the existing tunnel, the change in shield support stress will have an impact on the existing tunnel. The authors mainly analyse the influence of the support stress ratio on the displacement and stress of existing tunnels when shield tunnels advance to different distances $(Z=0 \cdot 25 D, Z=$ $0.50 D, Z=0 \cdot 75 D)$. Figure 5 shows the displacement and stress nephograms of existing tunnels when the support stress ratio changes and $Z$ is $0 \cdot 50 \mathrm{D}$. Considering the influence of different support pressure ratios on the deformation of existing tunnels, it can be found that when the support pressure ratio increases, the influence on existing tunnels will increase. For the deformation of existing tunnels under the same support pressure ratio, the deformation value will be more significant with the increase in distance.

Figures 6-8 show the vertical deformation curves of existing tunnels (top). From Figures 6-8, it can be found that the displacement and stress of existing tunnels are increasing with the decrease in support stress on the excavation face. The supporting pressure used in the

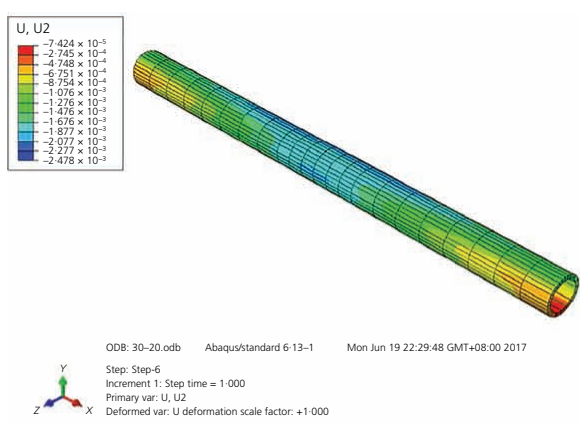

(a)
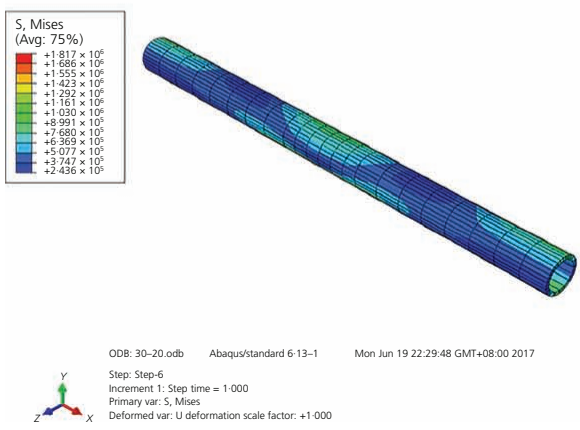

(d)

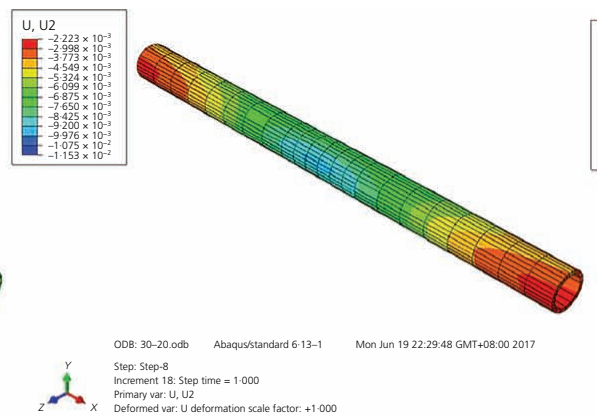

(b)
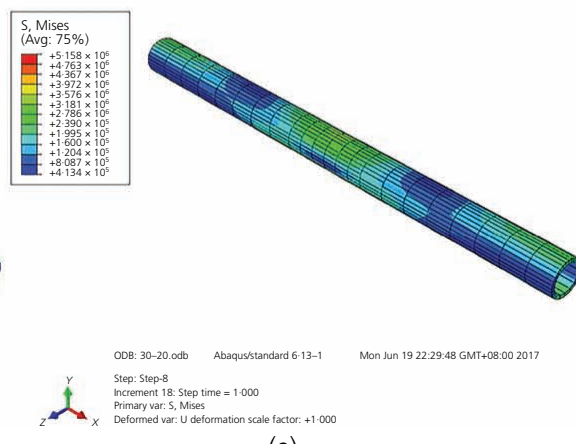

(e)

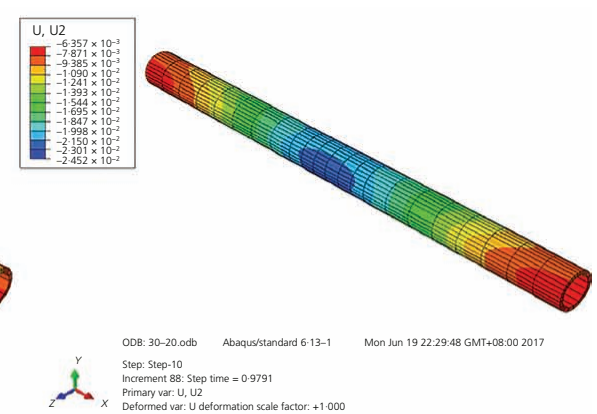

(c)
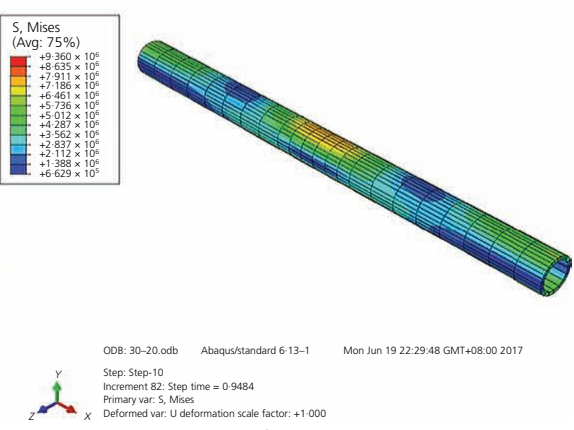

(f)

Figure 5. Displacement and stress nephograms of the existing tunnel $(Z=0 \cdot 50 D)$ : (a) displacement nephogram at $\lambda=0 \cdot 5$; (b) displacement nephogram at $\lambda=0 \cdot 3$; (c) displacement nephogram at $\lambda=0 \cdot 1$; (d) stress nephogram at $\lambda=0.5$; (e) stress nephogram at $\lambda=0 \cdot 3$; (f) stress nephogram at $\lambda=0 \cdot 1$ 
Stability of the excavation face on a

shield tunnel crossing beneath an

existing tunnel

Xue and Zhang

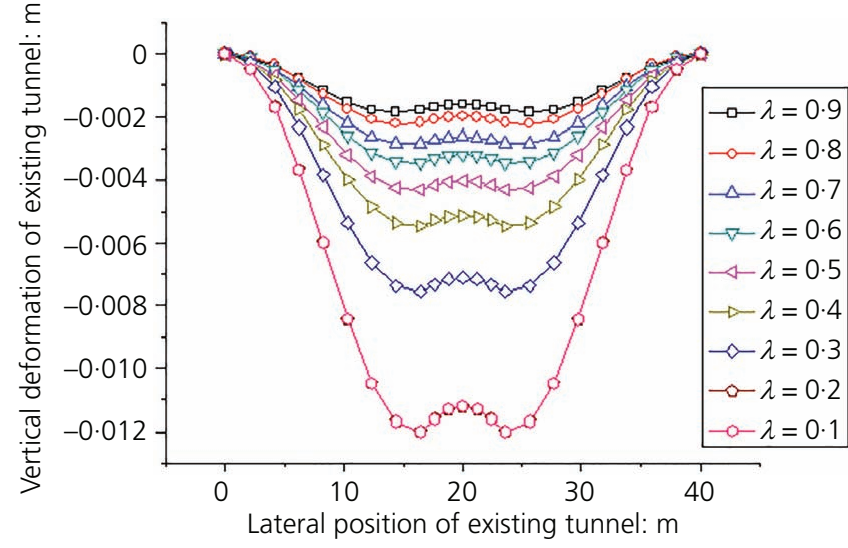

Figure 6. Vertical deformation curve of the existing tunnel at $Z=0 \cdot 25 D$

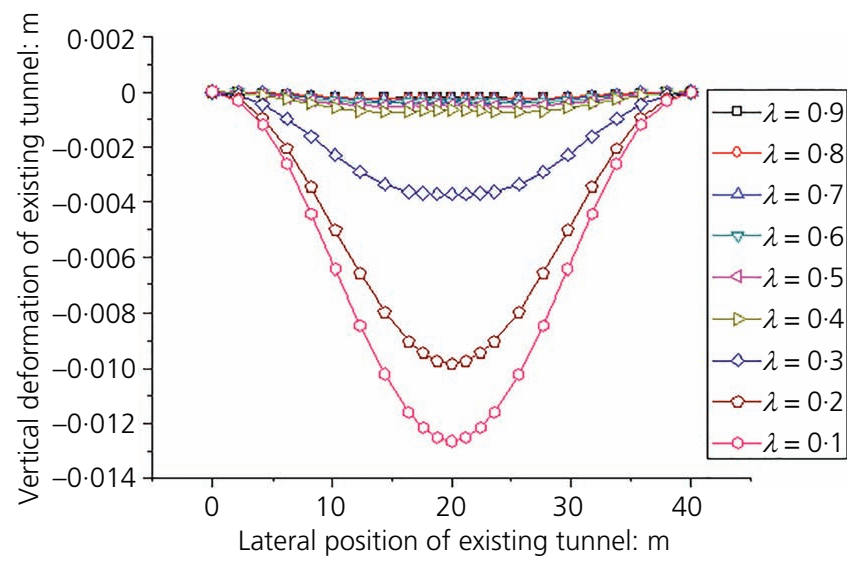

Figure 7. Vertical deformation curve of the existing tunnel at $Z=0.50 D$

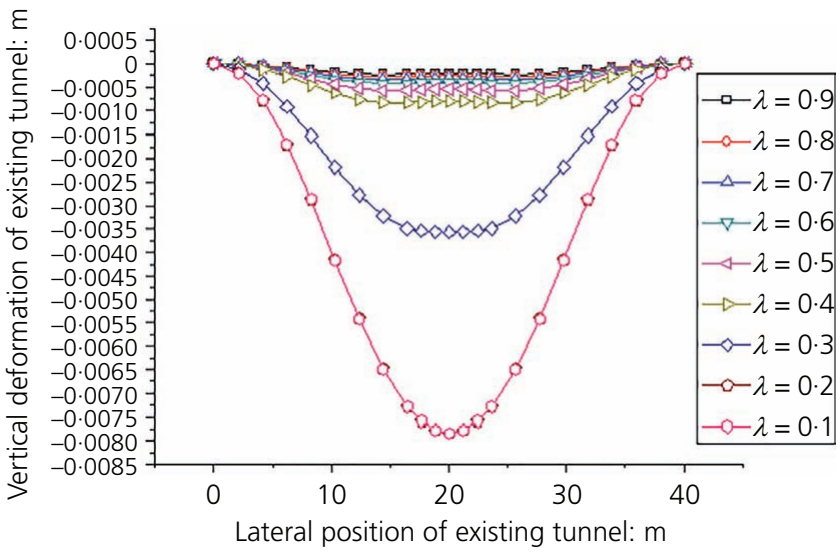

Figure 8. Vertical deformation curve of the existing tunnel at $Z=0.75 D$ excavation of new tunnels has a significant impact on the existing tunnels. When $Z$ is $0 \cdot 25 D$, the deformation of the segment top of the existing tunnel is larger. In comparison, when $Z$ is $0.50 D$ and $Z$ is $0 \cdot 75 D$, the deformation of the segment top of the existing tunnel due to the disturbance of the new tunnel will decrease with the decrease in the support stress ratio. Through the simulation of these working conditions, it is found that when the shield is pushed to the same position, different supporting pressures will produce different vertical deformation increments for new tunnel segments.

\section{Conclusion}

- When the horizontal distance between the excavation face and the existing tunnel is $0 \cdot 25 D$, the existing tunnel has almost no influence on the excavation face. By comparing the curves under different working conditions, it can be seen that when crossing approaches $(Z=0.75 D$ and $Z=0.50 D)$, the limit support pressure needed to maintain the balance of the excavation face of the existing tunnel is larger than that of the existing tunnel and the limit support force of the excavation face is slightly larger at $0.50 \mathrm{D}$ than that at $0.75 \mathrm{D}$.

- With the increase in the support stress ratio, the surface settlement curve above the existing tunnel tends to be gentle and the depth of the settlement trough decreases. At the same time, the surface settlement of the existing tunnel is smaller than that of the case with no existing tunnel, but the influence range is widened. The reason is that the stiffness of the existing tunnel is much larger than that of the surrounding soil, which results in the shielding effect reducing the surface settlement and the excavation unloading effect is transmitted to a farther area. This shows that the existence of the existing tunnel has a significant impact on the ground settlement caused by the excavation of the new tunnel.

- When $Z$ is $0 \cdot 25 D$, the stress ratio of the limit support is less than $0 \cdot 3$, which is a significant change area of the surface directly above the existing tunnel. When $Z$ is $0.50 D$ and $Z$ is $0 \cdot 75 D$, the stress ratio of the limit support is less than $0 \cdot 4$, which is a significant change area of the surface above the existing tunnel. When there is no existing tunnel, the stress ratio of the limit support is less than $0 \cdot 3$, which is a significant change area of the surface. Therefore, keeping the support pressure of the shield tunnelling face away from these significant changing areas is important in controlling the deformation of the existing tunnel.

- The supporting pressure used in the excavation of new tunnels has a significant impact on the existing tunnels. When $Z$ is $0 \cdot 25 D$, the deformation of the segment top of the existing tunnel is larger. Compared with $Z$ is $0.50 D$ and $Z$ is $0.75 D$, the deformation of the segment top of the existing tunnel due to the disturbance of the new tunnel will decrease with the decrease in the support stress ratio. Through the simulation of the aforementioned working conditions, it is found that when the shield is pushed to the same position, different supporting pressures will produce different vertical deformation increments for new tunnel segments. 


\section{REFERENCES}

Addenbrooke TI and Potts DM (2001) Twin tunnel interaction: surface and subsurface effects. International Journal of Geomechanics 1(2): 249-271, https://doi.org/10.1061/(asce)1532-3641(2001)1:2(249).

Anagnostou G and Kovari K (1994) The face stability of slurry shielddriven tunnels. Tunneling and Underground Space Technology 9(2): 165-174, https://doi.org/10.1016/0148-9062(94)90438-3.

Chapman DN, Ahn SK and Hunt DVL (2007) Investigating ground movements caused by the construction of multiple tunnels in soft ground using laboratory model tests. Canadian Geotechnical Journal 44(6): 631-643, https://doi.org/10.1139/T07-018.

Chen RP, Tang L, Ling D and Chen YM (2011) Face stability analysis of shallow shield tunnels in dry sandy ground using the discrete element method. Computers and Geotechnics 38(2): 187-195, https://doi.org/ 10.1016/j.compgeo.2010.11.003.

Gao D (2011) Transfer mechanism and calculation of vertical earth pressure of shield tunnel in sandy soil. Highway 11(2): 214-217 (in Chinese).

Hefny AM, Chua HC and Zhao J (2004) Parametric studies on the interaction between existing and new bored tunnels. Tunneling and Underground Space Technology 19(4-5): 471, https://doi.org/10.1016/ j.tust.2004.02.074.

Hu XY and Zhang ZX (2013) Study on simulation method of particle flow in unstable state of slurry shield excavation face under different stratum conditions. Chinese Journal of Rock Mechanics and Engineering 8(11) 2258-2267 (in Chinese).

Jancsecz S and Steiner W (1994) Face support for a large Mix-Shield in heterogeneous ground conditions. In Tunneling '94. Springer, Dordrecht, the Netherlands, pp. 531-550.

Lee KM and Ge XW (2001) The equivalence of a jointed shield-driven tunnel lining to a continuous ring structure. Canadian Geotechnical Journal 38(3): 461-483, https://doi.org/ 10.1139/cgj-38-3-461.

Li J, Chen RP and Ling G (2011) Experimental study on instability mode of shield excavation face and soil arching effect in dry sand. China Civil Engineering Journal 44(7): 142-148 (in Chinese).

Li L, Zhang MX, Wu HM and Wang YJ (2014) Influence of short-distance multi-line overlapped shield tunneling on deformation of existing tunnels. Chinese Journal of Geotechnical Engineering 36(6): 1036-1043, https://doi.org/10.11779/CJGE201406007.

Ma J, Sun SZ, Rui HT et al. (2016) Review on China's traffic engineering research progress. China Journal of Highway and Transport 29(6): 1-161, https://doi.org/10.19721/j.cnki.1001-7372.2016.06.001 (in Chinese)
Miao LC, Wang ZX and Shi WB (2015) Theoretical and numerical simulations of face stability around shield tunnels in sand. Chinese Journal of Geotechnical Engineering 37(1): 98-104, https://doi.org/10. 11779/CJGE201501011 (in Chinese)

Peck RB (1969) Deep excavations and tunnelling in soft ground. Proceedings of the 7th International Conference on Soil Mechanics and Foundation Engineering, Mexico City, Mexico, vol. 4, pp. 225-290.

Protodyakonov MM (1907) Rock Pressure on Mine Support (Theory of Mine Support). Tipografiya Gubernskogo Zemstva, Yekaterinoslav, Russia (in Russian).

Roberts I (1883) Determination of the vertical and lateral pressures of granular substances. Proceedings of the Royal Society of London 36(228-231): 225-240, https://doi.org/10.1098/rspl.1883.0106.

Song JH, Chen KF and Li NN (2015) Analysis of the influence of soil and water coupling on the soil arch effect and the minimum support force of shield. Journal of the China Railway Society 37(10): 122-128, https://doi.org/10.3969/j.issn.1001-8360.2015.10.017 (in Chinese)

Terzaghi K (1936) Stress distribution in dry and in saturated sand above a yielding trap-door. Proceedings of the 1st Conference of Soil Mechanics and Foundation Engineering, Boston, MA, USA, pp. 307-316.

Terzaghi K (1943) Arching in ideal soils. In Theoretical Soil Mechanics. Wiley, New York, NY, USA, pp. 66-76.

Wu J, Liao SM and Shi ZH (2015) Stability of shield tunnel excavation face considering soil arch effect. Journal of Tongji University 43(2): 213-220, https://doi.org/10.11908/j.issn.0253-374x.2015.02.008 (in Chinese).

Xiao X, Zhang MX, Wu HM and Zhang ZG (2011) Numerical simulation analysis on ground settlements caused by multi-line shield tunnel. Journal of Underground Space and Engineering 7(5): 884-889, https://doi.org/10.1097/RLU.0b013e3181f49ac7.

Xu M, Zou WH and Liu Y (2012) Face stability of large slurry shielddriven tunnel in sands. China Civil Engineering Journal 45(3): 174-181 (in Chinese).

Yu N and Zhu HH (2002) Analysis of earth deformation caused by shield tunnel construction and 3D-FEM simulation. Rock and Earth Mechanics 25(8): 1330-1334, https://doi.org/10.1007/BF02911033.

Zhang ZX, Hu XY and Kieffer DS (2011) A discrete numerical approach for modelling face stability in slurry shield tunnelling in soft soils. Computers and Geotechnics 38(1): 94-104, https://doi.org/10.1016/j. compgeo.2010.10.011.

\section{How can you contribute?}

To discuss this paper, please submit up to 500 words to the editor at journals@ice.org.uk. Your contribution will be forwarded to the author(s) for a reply and, if considered appropriate by the editorial board, it will be published as a discussion in a future issue of the journal. 